9) W. Droste, H.D. Scharf, F. Korte, Ann. Chem., 724, 71 (1969).

10) C. Berger, M.F. Neumann, G. Qurisson, Tetrahedron Lett., 1968, 3451.

11) T. Saegusa, I. Murase, Y. Ito, Bull. Chem. Soc. Jpn., 45, 1884 (1972).

12) L.G. Tensmeyer, C. Ainsworth, J. Org. Chem., 31, 1878 (1966).

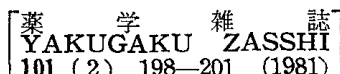

Tulobuterol の生体内運命 (第 5 報 ${ }^{1)}$ ) ラット，イヌ，モルモットおよび ウサギにおける代謝および排泄に関する種差

松村阜子, ${ }^{*},{ }^{a}$ 高原義男, ${ }^{a}$ 荒谷隆幸, ${ }^{a}$ 西出和憲, ${ }^{a}$ 加藤日出男, ${ }^{a}$ 桐山典城 ${ }^{b}$ 北陸製薬株式会社中央研究所, ${ }^{a}$ 北陸大学薬学部 $b$

\title{
Studies on the Metabolic Fate of Tulobuterol. V.1) Species Differences in the Metabolism and Excretion in Rat, Dog, Duinea Pig and Rabbit \\ Kugako Matsumura, ${ }^{*}, a$ Yoshio Takahara, ${ }^{a}$ Takayuki Aratani, $^{a}$ Kazunori Nishide, ${ }^{a}$ Hideo Kato, ${ }^{a}$ and Noriki Kiriyama ${ }^{b}$ Hokuriku Seiyaku Co., Ltd., ${ }^{a}$ Inokuchi, Katsuyama, Fukui and Faculty of Pharmaceutical Sciences, Hokuriku University ${ }^{b}$ Kanagawa-cho, Kanazawa
}

(Received October 3, 1980)

The species differences in the metabolism and excretion of tulobuterol (I) were investigated in rat, dog, guinea pig and rabbit after oral administration of ${ }^{14} \mathrm{C}$-tulobuterol.

The urinary metabolites were analyzed by thin-layer chromatography.

The urinary excretion of radioactivity within $72 \mathrm{hr}$. was estimated and about $50 \%$ of the administered dose were excreted in the urine of rat, dog and guinea pig, whereas relatively a small amount (24.6\% of dose) in the urine of rabbit.

The excretion of ${ }^{14} \mathrm{CO}_{2}$ into expired air within $48 \mathrm{hr}$. was $19.6 \%$ and $35.8 \%$ of dose in guinea pig and rabbit, respectively, and these values were larger than $0.8 \%$ in rat.

Major metabolites excreted in the urine were 3-hydroxy-(III) and 4-hydroxy-5methoxytulobuterol (IV) in rat, IV and $o$-chloromandelic acid (VI) in dog, an unchanged drug, 1-(o-chlorophenyl)-1,2-ethandiol (V) and IV in guinea pig, and VI in rabbit.

On the basis of these results it was clarified that there were marked species differences in the metabolism and excretion of I.

Keywords_-species differences; metabolism; excretion; tulobuterol; bronchodilator<smiles>[R19]c1cc(C([R4])O)c(Cl)c([R4])c1Cl</smiles>

\begin{tabular}{lllll} 
& $\mathrm{R}_{1}$ & $\mathrm{R}_{2}$ & $\mathrm{R}_{3}$ & \multicolumn{1}{c}{$\mathrm{R}_{4}$} \\
I & $\mathrm{H}$ & $\mathrm{H}$ & $\mathrm{H}$ & $-\mathrm{CH}_{2} \mathrm{NHC}\left(\mathrm{CH}_{3}\right)_{3}$ \\
II & $\mathrm{H}$ & $\mathrm{OH}$ & $\mathrm{H}$ & $-\mathrm{CH}_{2} \mathrm{NHC}\left(\mathrm{CH}_{3}\right)_{3}$ \\
III & $\mathrm{OH}$ & $\mathrm{H}$ & $\mathrm{H}$ & $-\mathrm{CH}_{2} \mathrm{NHC}\left(\mathrm{CH}_{3}\right)_{3}$ \\
IV & $\mathrm{H}$ & $\mathrm{OH}$ & $\mathrm{OCH}_{3}$ & $-\mathrm{CH}_{2} \mathrm{NHC}\left(\mathrm{CH}_{3}\right)_{3}$ \\
V & $\mathrm{H}$ & $\mathrm{H}$ & $\mathrm{H}$ & $-\mathrm{CH}_{2} \mathrm{OH}$ \\
VI & $\mathrm{H}$ & $\mathrm{H}$ & $\mathrm{H}$ & $-\mathrm{COOH}$
\end{tabular}

Fig. 1. Structure of Tulobuterol and Its Metabolites in Rat Urine
Phenethylamine 誘導体である tulobuterol (I) は adrenergic $\beta$-recepter 刺激による気管支拡張剤で， その作用は気管支筋に対し選択的であり，かつ持続 的であることが報告されている.22ささきに著者らは Iのラットでの生体内運命について検討し, ${ }^{3)}$ 経口投 与時での尿中代謝物として未変化体の活か 4-hydroxy-(II), 3-hydroxy-(III), 4-hydroxy-5-methoxytulobuterol (IV), 1-(o-chlorophenyl)-1,2-ethanediol (V) および $o$-chloromandelic acid (VI) を同 定し (Fig. 1), 主代謝物経路が芳香環水酸化反応 であることを明らかとした。一方経口投与時に和け 
るヒト尿中からも芳香環水酸化体が検出され，4）類似構造を有するclorprenaline ${ }^{5)}$ とは異なる代謝経路で代謝さ れていることが示唆された.

そこで今回，ラットを含めた各種動物での経口投与時に特ける排泄量ならびに尿中代謝物に祘ける種差につい て比較検討したので報告する.

\section{実験 方 法}

標識化合物 Diethyl $2-{ }^{14} \mathrm{C}$-malonate（第一化学薬品）を出発原料として前報 ${ }^{3 a}$ ) の力法にしたがって合成し た ${ }^{14} \mathrm{C}$-tulobuterol (メチレン炭素をラベル) を用いた。

使用動物および投与方法＼cjkstart雄性の SD 系ラット (200--250 g), ビーグル犬 $(9-11 \mathrm{~kg})$, Hartley 系モルモッ ト $(310-350 \mathrm{~g})$ および白色在来種ウサギ $(2.0-2.5 \mathrm{~kg})$ を 24 時間絶食後実験に供した. イヌでは ${ }^{14} \mathrm{C}-\mathrm{tulo}$ buterol をカプセルに入れて $1 \mathrm{mg} / \mathrm{kg}$ 経口投与した. ラット，モルモットおよびウサギでは ${ }^{14} \mathrm{C}$-tulobuterol を 水溶液とし， $2 \mathrm{mg} / \mathrm{kg}$ 胃ゾンデを用いて胃内へ強制投与した. なお, 飼料は投与 1 時間目より与光, 水は絶食 中も自由に与えた.

尿, 䔬, 呼気中排泄率の測定前報 $3 a$ ) 飞準じて処理し，所定時間毎に放射能を測定した。な拉，呼気中排 泄についてはラット，モルモットおよびウサギで行なった。

尿中代謝物の分離採取した尿 $10 \mathrm{ml}$ を conc. $\mathrm{NH}_{4} \mathrm{OH}$ で pH 9.5 に調整し, ethyl acetate $10 \mathrm{ml}$ で 3 回 抽出する. この ethyl acetate 層を $10 \mathrm{ml}$ をで減王留去し $0.1 \mathrm{~N} \mathrm{HCl} 10 \mathrm{ml}$ で抽出し，水層部へ移行する塩基性 部と ethyl acetate 層に残留する中性部に分画した. 最初の水層部は conc. HCl で pH 2.5 とし, ethyl acetate $10 \mathrm{ml}$ で抽出, ethyl acetate 層に移行する酸性部と移行しない水溶性部に分画した. 抱合体については水 溶性部を $5 \% \mathrm{HCl}$ で 3 時間加熱して加水分解後, 前述の方法で塩基性部, 中性部, 酸性部拉よび水溶性部に分 画し，それぞれの放射能を測定した.

尿中代謝物の定量＼cjkstart塩基性部，中性部扣よび酸性部につき薄層クロマトグラフィーを行い，前報 ${ }^{3 b 2}$ に準じ て代謝物を定量した．たたし，展開溶媒としては塩基性・中性代謝物の分離には A) $\mathrm{CHCl}_{3}-\mathrm{CH}_{3} \mathrm{OH}-\mathrm{Conc}$. $\mathrm{NH}_{4} \mathrm{OH}(77: 20: 3 \mathrm{v} / \mathrm{v})$ を，酸性代謝物の分離には B) benzene: acetone: ethyl acetate $(50: 50: 3)$ を用いた。

\section{結果および考察}

${ }^{14} \mathrm{C}-\mathrm{Tulobuterol}$ の経口投与後 72 時間までの尿・粪中排泄量（Table I） 抢よび 48 時間までの呼気中排泄量 (Table II) を比較した.

ラット执よびイスでは尿・䔬中排泄量が $80 \%$ 以上であるが，モルモットおよびウサギは少なく，呼気中排泄

TABLE I. Cumulative Urinary and Fecal Excretion of Radioactivity after Oral Administration of ${ }^{14} \mathrm{C}$-Tulobuterol in Various Animals

\begin{tabular}{|c|c|c|c|c|c|}
\hline \multirow{2}{*}{ Animals } & \multirow{2}{*}{$\begin{array}{l}\text { Time } \\
\text { (hr) }\end{array}$} & \multirow{2}{*}{$\begin{array}{c}\text { Dose } \\
(\mathrm{mg} / \mathrm{kg})\end{array}$} & \multicolumn{3}{|c|}{$\%$ of dose } \\
\hline & & & Urine & Feces & Total \\
\hline \multirow[t]{3}{*}{ Rat } & $0-24$ & 2 & $46.3 \pm 2.0$ & $30.7 \pm 1.0$ & 77.0 \\
\hline & $0-48$ & & $47.7 \pm 1.8$ & $32.9 \pm 0.9$ & 80.6 \\
\hline & $0-72$ & & $48.2 \pm 1.8$ & $33.9 \pm 1.1$ & 82.1 \\
\hline \multirow[t]{3}{*}{ Dog } & $0-24$ & 1 & $46.7 \pm 2.7$ & $30.3 \pm 2.4$ & 79.0 \\
\hline & $0-48$ & & $51.2 \pm 2.9$ & $32.1 \pm 2.5$ & 83.3 \\
\hline & $0-72$ & & $52.0 \pm 3.0$ & $32.7 \pm 2.5$ & 84.7 \\
\hline \multirow[t]{3}{*}{ Guinea pig } & $0-24$ & 2 & $46.3 \pm 2.1$ & $10.8 \pm 0.9$ & 57.1 \\
\hline & $0-48$ & & $47.4 \pm 2.0$ & $17.3 \pm 1.0$ & 64.7 \\
\hline & $0-72$ & & $47.7 \pm 2.0$ & $18.8 \pm 0.8$ & 66.5 \\
\hline \multirow[t]{3}{*}{ Rabbit } & $0-24$ & 2 & 23. $0 \pm 1.0$ & $6.5 \pm 0.8$ & 29.5 \\
\hline & $0-48$ & & $23.8 \pm 1.2$ & $7.4 \pm 0.6$ & 31.2 \\
\hline & $0-72$ & & $24.6 \pm 0.8$ & $8.0 \pm 0.7$ & 32.6 \\
\hline
\end{tabular}

Each value is expressed as the mean S.E. of three animals. 
TABle II. Percent Recovery of ${ }^{14} \mathrm{C}$ in Expired $\mathrm{CO}_{2}$ after Oral Administration of ${ }^{14} \mathrm{C}$-Tulobuterol in Various Animals

\begin{tabular}{lccr}
\hline \hline Animals & $\begin{array}{c}\text { Time } \\
(\mathrm{hr})\end{array}$ & $\begin{array}{c}\text { Dose } \\
(\mathrm{mg} / \mathrm{kg})\end{array}$ & \multicolumn{1}{c}{${ }^{{ }^{4}} \mathrm{CO}_{2}$} \\
\hline Rat & $0-24$ & 2 & $0.6 \pm 0.2$ \\
& $0-48$ & & $0.8 \pm 0.1$ \\
Guinea pig & $0-24$ & 2 & $18.3 \pm 1.1$ \\
& $0-48$ & & $19.6 \pm 1.1$ \\
Rabbit & $0-24$ & 2 & $35.0 \pm 1.5$ \\
& $0-48$ & & $35.8 \pm 1.4$ \\
\hline
\end{tabular}

Each value is expressed as the mean S.E. of three animals.

TABLE III. Metabolites in Basic, Neutral and Acidic Fraction of Urine in Various Animals

\begin{tabular}{|c|c|c|c|c|c|c|c|c|c|c|c|c|c|}
\hline \multirow{4}{*}{ Animals } & \multicolumn{13}{|c|}{$\%$ of dose } \\
\hline & \multicolumn{8}{|c|}{ Basic metabolites } & \multirow{2}{*}{\multicolumn{2}{|c|}{$\begin{array}{c}\text { Neutral } \\
\text { metabolite } \\
\text { V }\end{array}$}} & \multirow{2}{*}{\multicolumn{2}{|c|}{$\begin{array}{c}\text { Acidic } \\
\text { metabolite } \\
\text { VI }\end{array}$}} & \multirow{3}{*}{ Total } \\
\hline & \multicolumn{2}{|c|}{ I } & \multicolumn{2}{|c|}{ III } & \multicolumn{2}{|c|}{ III } & \multicolumn{2}{|c|}{ IV } & & & & & \\
\hline & $\mathrm{F}$ & C & $\mathrm{F}$ & C & $\mathrm{F}$ & C & $\mathrm{F}$ & $\vec{C}$ & $\mathrm{~F}$ & C & F & C & \\
\hline Rat & 2.1 & 0.1 & 0.1 & 1.2 & 0.5 & 14.0 & 0.3 & 12.0 & 0.1 & 0.1 & 0.9 & n.d. & 31.4 \\
\hline Dog & 1.9 & 0.1 & 0.4 & 0.3 & 0.2 & 1.1 & 1.1 & 2.8 & 0.3 & 0.8 & 4.5 & 0.1 & 13.6 \\
\hline Guinea pig & 8.8 & 0.2 & 2.1 & 1.0 & \multicolumn{2}{|c|}{ n.d. } & 0.2 & 0.5 & 5.5 & 3.5 & 8.0 & 0.1 & 29.9 \\
\hline Rabbit & 0.3 & n.d. & n.d. & 1.0 & n. & & \multicolumn{2}{|c|}{ n.d. } & 0.3 & 1.4 & 7.6 & 0.2 & 10.8 \\
\hline
\end{tabular}

F: Free, C: Conjugated, n.d.: not detected.

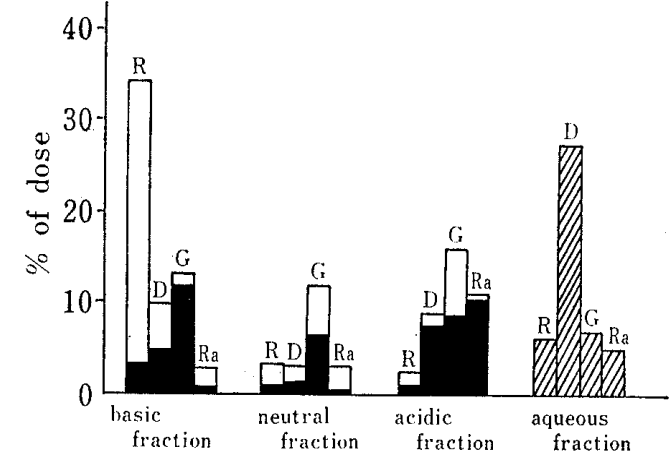

Fig. 2. Distribution of Radioactivity among Basic, Neutral, Acidic and Aqueous Fractions of Various Animals Urine after Oral Administration of ${ }^{14} \mathrm{C}$-Tulobuterol

R: rat, D: dog, G: guinea pig, Ra: rabbit, $\square$ : conjugated,
量を考慮すればモルモット $86 \%$ ，ウサギ $68 \%$ に達するも ののラットとは本質的に異なる代謝経路が示唆された. そ こで各動物の 24 時間尿を塩基性, 中性, 酸性および水溶 性分画にわけ，それぞれの代謝物を定量し，さらに水溶性 部を $5 \% \mathrm{HCl}$ で加水分解し同様に操作したものを抱合体 の量としてあらわし比較した (Fig. 2, Table III)。

テットでは塩基性分画が尿中排泄量の $74.1 \%$ を占めそ の $81.9 \%$ がフェノール化され，そのほとんどが $(96.8 \%)$ 抱合化されていた. イヌでは水溶性分画が尿中排泄量の $56.1 \%$ を占め, ラットとは異なる代謝経路が存在してい ることが示唆されたが，それが単に抱合体の種類が異なる のか，別の代謝物が存在するのかは明らかではない，残る 分画についてはフェノール化された代謝物と側鎖が酸化さ れた代謝物が同程度の割合で検出された。モルモットでは 塩基性，中性および酸性分画が尿中排泄量に対して $28.3 \%$,

$25.5 \%$ 叔よび $32.6 \%$ と大差はないが，塩基性分画の $98 \%$ が未变化体であることからラットとは全く異なる経

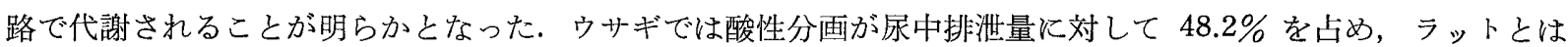
異なる経路で代謝されるが，中性分画拉よび代謝物が少ないことはモルモットとも異なっていた。

すなわら今回の結果から各動物の代謝経路を推察すると（Fig. 3)，ラットでは芳香環水酸化が主代謝経路であ り，モルモット拈よびウサギでは側鎖の酸化とくに ${ }^{14} \mathrm{CO}_{2}$ の排泄がラットより多いことからo-chlorobenzyl al- 


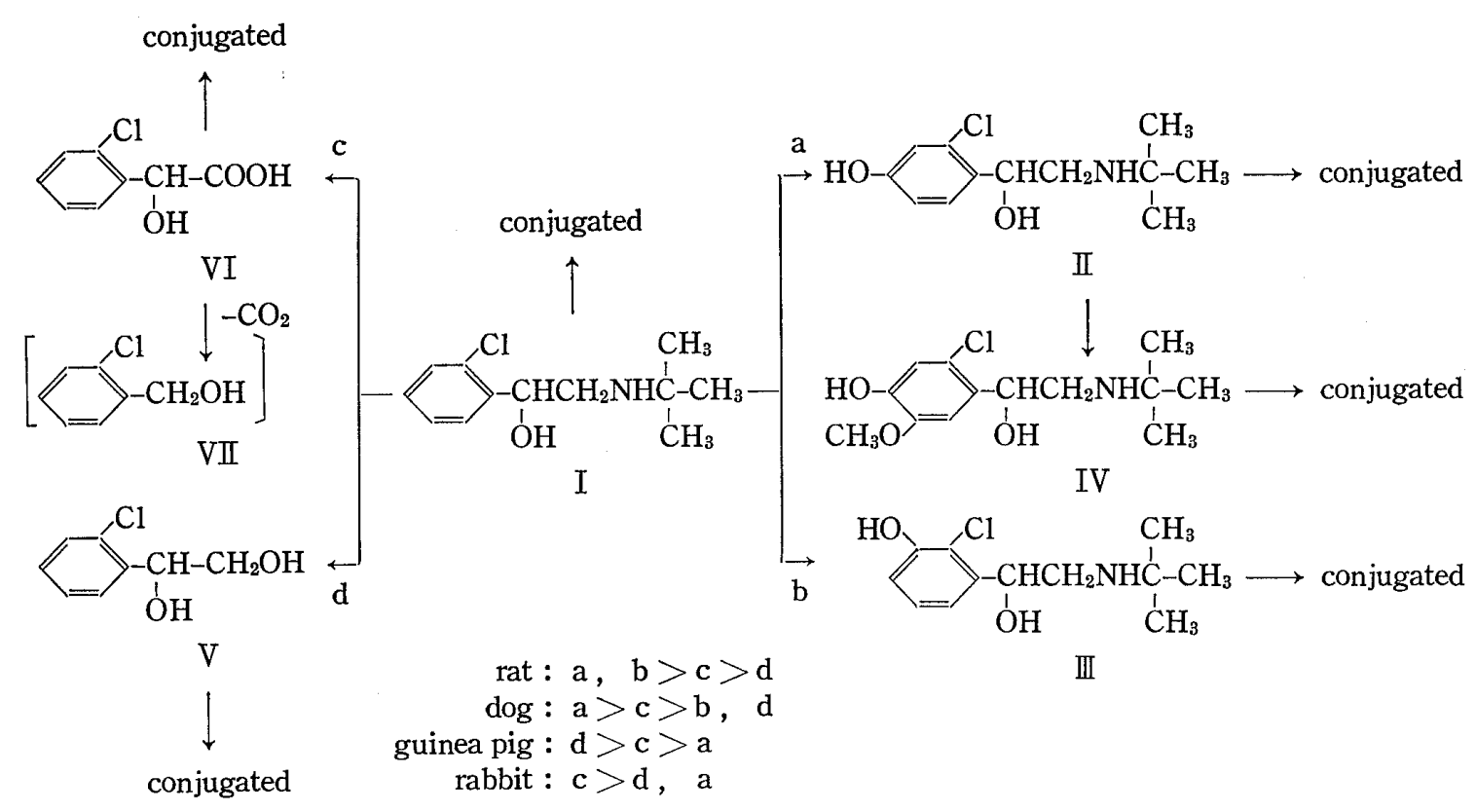

Fig. 3. Possible Metabolic Pathways in Various Animals

cohol (VII) を経てさらに o-chlorobenzoic acid となる経路が主代謝経路と考えられる.イスについては未知代 謝物が多く，主代謝経路の解明にはいたらずさらに検討を要する。

これらの結果, 活性代謝物 ${ }^{6)}$ を含む塩基性代謝物が検出されたラットやイヌがヒトに比較的類似していること が示唆され，この点がヒトでの代謝が側鎖酸化のウサギに類似している clorprenaline とは全く異なって括り， 両薬物の臨床上での効果の違いが示唆された.

\section{引用文献および注}

1）第 4 報：高原義男, 荒谷隆幸, 西出和憲, 松村阜子, 加藤日出男, 桐山典城, 薬誌, 100, 1241 (1980).

2) a) S. Kubo, Y. Kase, T. Miyata, I. Uesaka, Arzneim-Forsch., 25, 1028 (1975); b) S. Kubo, I. Uesaka, I. Matsubara, I. Ishihara, Y. Kase, Arzeim-Forsch., 27, 1439 (1977).

3）a）第 1 報：上坂征夫, 荒谷隆幸, 西出和憲, 越中栄一, 新田啓一, 山本 譲, 医薬品研究, 7, 548 (1976);

b) 第 2 報: 山本 譲, 樋口昭幸, 藤橋俊明, 清水 栄, 西出和憲, 上坂征夫, 薬誌, 97, $244(1977) ； c$ ) 第 3 報：山本 譲, 新田啓一, 藤橋俊明, 上坂征夫, 西出和憲, 薬誌, 97, 231 (1977).

4) K. Matsumura, O. Kubo, T. Sakashita, Y. Adachi, H. Kato, K. Watanabe, M. Hirobe, J. Chromatogr., 印刷中.

5) K. Tatsumi, N. Arita, C. Yamato, H. Yoshimura, H. Tsukamoto, Chem. Pharm. Bull., 18, 1254 (1970).

6) a) Y. Gomi, H. Shirahase, H. Funatsu, Japan Pharmacol, 29, $515(1979)$; b ) 越中栄一, 倉田 采, 山岸 輝里, 久保信治, 加藤日出男, 薬誌, 98, 1198 (1978). 